\title{
Highly Restricted Human T Cell Repertoire in Peripheral Blood and Tissue-infiltrating Lymphocytes in Omenn's Syndrome
}

\author{
Frédéric Rieux-Laucat, ${ }^{*}$ Philippe Bahadoran, ${ }^{\ddagger}$ Nicole Brousse, ${ }^{\ddagger}$ Françoise Selz, ${ }^{\star}$ Alain Fischer, ${ }^{*}$ Françoise Le Deist, ${ }^{\star}$ \\ and Jean Pierre De Villartay* \\ *Unité INSERM 429 and ${ }^{\ddagger}$ Service d’Anatomopathologie, Hôpital Necker-Enfants Malades, 75743 Paris, Cedex 15, France
}

\begin{abstract}
Omenn's syndrome is an inherited human combined immunodeficiency condition characterized by the presence of a large population of activated and tissue-infiltrating $T$ cells. Analysis of the TCRB repertoire revealed a highly restricted TCRBV usage in three patients. More strikingly, $T$ cell clones from the three patients expressed TCRB chains with VDJ junction similarities, suggesting a common antigenic specificity. Analysis of the TCRA repertoire in one patient also revealed a restricted TCRAV usage. Finally, analysis of the TCRBV repertoire of tissue-infiltrating $T$ cells in one patient suggested nonrandom tissue migration. These results suggest that the oligoclonal expansion of $\mathrm{T}$ cells observed in Omenn's syndrome could be the consequence of autoimmune proliferation generated by a profound defect in lymphocyte development. (J. Clin. Invest. 1998. 102:312321.) Key words: combined immunodeficiency • Omenn syndrome $\bullet$ T lymphocytes $\bullet \mathrm{HTCRBV} \cdot$ repertoire
\end{abstract}

\section{Introduction}

Omenn's syndrome, also known as combined immunodeficiency with hypereosinophilia, is a primary recessive inherited immunodeficiency with specific clinical and immunological features. In addition to the severe recurrent infections occurring in severe combined immunodeficiency (SCID), ${ }_{1}^{1}$ patients with Omenn's syndrome rapidly develop diffuse erythroderma and protracted diarrhea, together with marked hypereosinophilia (1). The number of circulating T cells is high but they are poorly responsive to antigens and allogenic cells (2-4), and their cytokine secretion pattern is markedly altered $(4,5)$. Contrasting with the severe depletion observed in lymphoid

F. Rieux-Laucat and P. Bahadoran contributed equally to this work. Address correspondence to Frédéric Rieux-Laucat, Unité INSERM 429, Hôpital Necker-Enfants Malades, 149 rue de Sèvres 75743 Paris, Cedex 15, France. Phone: 33-144-492527; FAX: 33-142-730-640; E-mail: rieux@necker.fr Philippe Bahadoran's present address is Service de Dermatologie, Hôpital Archet 2, 06000 Nice, France.

Received for publication 4 April 1997 and accepted in revised form 30 April 1998.

1. Abbreviations used in this paper: A-PCR, anchored PCR; SCID, severe combined immunodeficiency; TCR, T cell receptor.

J. Clin. Invest.

(C) The American Society for Clinical Investigation, Inc. 0021-9738/98/07/0312/10 \$2.00

Volume 102, Number 2, July 1998, 312-321

http://www.jci.org tissues, large numbers of $\mathrm{T}$ cells also infiltrate the skin and intestine (6). B cells are absent or scarce in both peripheral blood and tissues, resulting in profound hypogammaglobulinemia (except for $\operatorname{IgE}$ ) (2).

We and others have found a restricted rearrangement pattern of T cell receptor (TCR) genes in patients with Omenn's syndrome $(2,3)$, pointing to limited $\mathrm{T}$ cell diversity. The presence of other clones in the $\mathrm{T}$ cell population could not be ruled out, owing to the limited sensitivity of Southern blot analysis. We now report the results of molecular analysis of the TCRB chain in three patients with Omenn's syndrome, with an anchored-PCR (A-PCR) amplification method. In addition, TCRBV chain diversity in tissue-infiltrating $T$ cells was also determined in one patient.

\section{Methods}

\section{Patients and controls}

Case reports on the three patients including peripheral blood lymphocyte phenotypes have been published elsewhere $(2,7)$. The absence of maternal engrafted $\mathrm{T}$ cells was confirmed in every case by either minisatellite analysis (2) or HLA typing (7). Briefly all patients had $>80 \%$ circulating T cells, comprising $30-57 \%$ of activated $\mathrm{Dr}^{+}$ cells. Among $\mathrm{CD}^{+}$cells, the percentages of $\mathrm{CD}^{+}$and $\mathrm{CD}^{+}$were as follows: patient 1,29 and 54\%; patient 2, 55 and $36 \%$; and patient 3 , 85 and $5 \%$. Peripheral blood lymphocytes from two healthy volunteers were used as controls for the A-PCR study. Skin biopsy samples from psoriatic patients served as controls for the immunohistochemical study. Samples were obtained from patients before bone marrow transplantation conditioning.

\section{Antibodies}

The following mAbs were used: anti-CD3: Leu4 (IgG2a) (Becton Dickinson, Mountain View, CA), anti-CD4: Leu3a (IgG1) (Becton Dickinson), anti-CD8: Leu2a (IgG1) (Becton Dickinson), anti-CD25 (IgG1) (Becton Dickinson), anti-HLA-DR (IgG2a) (Becton Dickinson), anti-TCRBV3 (IgG1), anti-TCRBV5a = anti-TCRBV5.2 ${ }^{+} 5.3$ (IgG1), anti-TCRBV5b = anti-TCRBV5.3 (IgG1) (all from T Cell Sciences, Cambridge, MA), anti-TCRBV2 (IgM), anti-TCRBV5.1 (IgM), anti-TCRBV6.1 (IgM), anti-TCRBV8 (IgG2a), anti-TCRBV9 (IgM), anti-TCRBV12 (IgG2a), anti-TCRBV13.1 (IgG2b), antiTCRBV13.6 (IgG1), anti-TCRBV14 (IgG1), anti-TCRBV16 (IgG1), anti-TCRBV17 (IgG1), anti-TCRBV18 (IgG2b), anti-TCRBV20 (Ig), and anti-TCRBV21 (IgG2b) (all from Immunotech, Marseille, France).

\section{Immunofluorescence study}

Lymphocyte phenotyping. Direct immunofluorescence staining was performed using FITC- or PE-conjugated antibodies. An FITC-conjugated goat anti-mouse Ig, GAMIG (Nordic Immunology, Tilburg, The Netherlands), was used for indirect immunofluorescence.

$T C R B V$ repertoire. Peripheral blood lymphocytes were incubated successively with an anti-TCRBV antibody, an FITC-conjugated GAMIG (Nordic), and a PE-conjugated anti-CD4 or anti-CD8 antibody. After each incubation, the cells were washed twice for 10 min at $4^{\circ} \mathrm{C}$ with $1 \times$ PBS. Background staining due to nonspecific fixation of the GAMIG was deducted. Samples were analyzed in a FACScan ${ }^{\circledR}$ flow cytometer (Becton Dickinson). 


\section{Immunohistochemistry}

Biopsy specimens of lymph node, spleen, skin, and intestine were embedded in Tissue Tek II O.C.T compound (Miles Laboratories, Inc., Elkhart, IN), snap-frozen in liquid nitrogen, and stored at $-70^{\circ} \mathrm{C}$ until use. For simple TCRBV immunostaining, consecutive 5-mm cryostat sections were incubated successively with a primary antibody, a biotin-conjugated rat anti-mouse Ig (Jackson Laboratories, West Grove, Pennsylvania, PA), and finally with alkaline phosphataseconjugated streptavidin (DAKO Corp., Carpinteria, CA). After each incubation, the slides were washed twice for $5 \mathrm{~min}$ at room temperature with Tris-HCl, pH 7.6. Alkaline phosphatase activity was detected with Naphthol-ASMX and Fast-blue (both from Sigma Chemical Co., St. Louis, MO). The results were expressed as - for the lack of positives or + for the presence of positive cells. In the skin, the number of cells bearing a given TCRBV was estimated by counting the cells in five contiguous high-power fields with a $20 \times$ objective.

\section{Analysis of the TCR repertoire}

PBMC were isolated on Ficoll/Hypaque gradients. PBMC were further purified into single positive CD4 and CD8 subsets (patients 1 and 2) by two-color fluorescence-activated cell sorting (FACStarplus $^{\circledR}$; Becton Dickinson) using FITC-Leu3a and PE Leu2a (Becton Dickinson), respectively. Total RNA from $\mathrm{PBMC}, \mathrm{CD}^{+}$, and $\mathrm{CD}^{+}$ cells was extracted as described elsewhere (8). 1-5 $\mu \mathrm{g}$ of total RNA was used for cDNA first-strand synthesis with $200 \mathrm{U}$ of MMLV reverse transcriptase (Superscript; GIBCO BRL, Gaithersburg, MD) and Oligo-dT (Pharmacia Biotech, Piscataway, NJ) according to the manufacturers' recommendations. After $1.5 \mathrm{~h}$ of elongation at $37^{\circ} \mathrm{C}$, cDNA was precipitated in isopropanol at $4^{\circ} \mathrm{C}$ for $15 \mathrm{~min}$, washed twice in $70 \%$ ethanol, and tailed with dGTP for $1 \mathrm{~h}$ at $37^{\circ} \mathrm{C}$ using terminal deoxynucleotidyl transferase (Boehringer Mannheim, Indianapolis, IN) according to the manufacturer's recommendations. The tailed cDNA was extracted with equal volumes of phenol and chloroform, precipitated in ethanol, and resuspended in $40 \mu \mathrm{l}$ of water. $10 \mu \mathrm{l}$ of the dG-tailed cDNA was amplified by means of A-PCR using TCRBC antisense primer and a "universal" sense primer containing MluI and SalI restriction sites, respectively. PCR amplifications were performed as described elsewhere (9). After digestion with SalI and MluI restriction enzymes, products corresponding to the mature VDJC transcripts were size-selected $(720 \pm 70 \mathrm{bp})$ on a $2 \%$ low-melting point agarose gel (Nusieve FMT) and ligated into the SalI-MluI sites of an M13 mp18-derived vector (M13 BM20; Boehringer Mannheim). The ligation products were introduced into XL1 Blue bacteria (Stratagene, La Jolla, CA) by electroporation to create the TCRB minilibraries. Minilibrary screenings were done with a panel of TCRBV- and TCRBJ-specific oligoprobes as described previously. The quantitative and qualitative aspects of this technique were previously demonstrated (9-11). TCRBV and TCRBJ frequencies were analyzed on $>600$ TCRBC-positive clones in the same experimental conditions for all probes. The following panel of oligonucleotides $\left(5^{\prime}-3^{\prime}\right)$ was used for TCRBJ and clone-specific analyses: TCRBJ1.1: AGGCACCAGACTCACAGTTG; TCRBJ1.2: GGGGACCAGGTTAACCGTTG; TCRBJ1.3: GGGAAGTTGGCTCACTGTTG; TCRBJ1.4: TGGAACCCAGCTCTCTGTCT; TCRBJ1.5: TGGGACTCGACTCTCCATCC; TCRBJ1.6: TGGGACCAGGCTCACTGTGA; TCRBJ2.1: AGGGACACGGCTCACCGTGC; TCRBJ2.2: AGGCTCTAGGCTGACCGTAC; TCRBJ2.3: AGGCACCCGGCTGACAGTGC; TCRBJ2.4: CGGGACCCGGCTCTCAGTGC; TCRBJ2.5: AGGCACGCGGCTCCTGGTGC; TCRBJ2.6: CGGCAGCAGGCTGACCGTGC; TCRBJ2.7: CGGGCACCAGGCTCACGGTC; DIVB13: GCCACCCGAACACTGAA; DIVB14a: GTTACTGCCCCTGAACAC and DIVB14b: GTTTGGGGTTCGATGAGC in patient 1; DIVB2: TTCCCTAGCGGGAAGACAGA and DIVB14c: TTTAGCCCCTTTGGAAGAAG in patient 3. Sequence analysis was performed using the $\mathrm{T} 7$ polymerase kit (Sequenase) with either vector-specific or TCRBV-specific primers. When CDR3 sequences were identical, clone independence was assessed by $\mathrm{G}$ tail length or by the cDNA start point.

For patient 2, TCRBV- and TCRAV-specific amplifications were performed using panels of primers and conditions described by Genevée et al. (12). Actin-specific primers (actin sense: ATTTGCGGTGGACGATGGAGGGGC; reverse: GGCATCGTCACCAACTGGGACGAC) were used as internal controls. Amplified products were run on a $1.2 \%$ agarose gel and detected by Southern blot analysis using either a TCRBC- or a TCRAC-specific oligoprobes (HTCRBC: CGGGCTGCTCCTTGAGGGGCTGCG; HTCRAC: GTTGCTCCAGGCCGCGGCACTGTT). Membranes were successively hybridized with an actin-specific oligoprobe (ATTTGCGGTGGACGATGGAGGGGC).

\section{Definition of CDR3 region}

For TCR junction comparisons we used the CDR3 definition of Moss and Bell (13). The CDR3 boundaries are determined as the fourth residue after Cys 90 and the last position preceding the consensus TCRBJ-contained Phe.

\section{Results}

Restricted TCRB and TCRA repertoire in Omenn's syndrome. In controls, all 24 TCRBV families were expressed normally in $\mathrm{CD}^{+}$and $\mathrm{CD}^{+} \mathrm{T}$ cells. Most frequencies were between 1 and $10 \%$ (range $0.5-18 \%$ ) (Fig. $1 A$ ). These results were in keeping with previous studies on normal human TCRBV gene usage $(9,10,14)$.

In striking contrast, the pattern of TCRBV family expression was drastically restricted in both $\mathrm{CD}^{+}$and $\mathrm{CD}^{+} \mathrm{T}$ cells from patients 1 and 2, as well as in unsorted $\mathrm{T}$ cells from patient 3. Fewer than 10 families were represented in each case (Fig. $1 \mathrm{~B}$ ). Moreover, major imbalances were observed in the frequency of these TCRBV families. Some accounted for up to $60-70 \%$ of the CD4 $4^{+}$(TCRBV13 in patient 1 and TCRBV6 in patient 2) or $\mathrm{CD}^{+}$subset (TCRBV14 in patient 1). Another intriguing feature observed was the recurrent expression of TCRBV families 6,14 , and 21 in all three patients. Several TCRBV families contain numerous gene members. Therefore, the restricted TCRBV pattern could have resulted from a selection process towards particular families, $\mathrm{V}$ gene usage being diverse. Sequencing the clones of each family showed that this restriction occurred at the level of TCRBV genes themselves. For example, the TCRBV6 family, which consists of nine functional gene segments, was overrepresented in patients 1 and 2, but the TCRBV6S1 and 6S4 genes alone accounted for all of the $\mathrm{TCRBV}^{+}$clones (see sequence analyses below). TCRBVspecific amplifications further illustrated the restricted pattern of TCRBV usage in patient 2. Indeed, this method detected 9 TCRBV families (TCRBV 1, 3-6, 9, 12, 14, and 15) in patient 2 (Fig. 2). TCRBV15 products were detected by bispecific PCR but not by A-PCR. This could reflect either the presence of few cells bearing these TCRBV specificities or weak crossamplifications related to the extreme conditions (see Methods and reference 12). This last explanation is probably true for TCRBV 8, 11, and 17, which gave very weak signals but remained undetectable both by A-PCR and immunofluorescence techniques. On the other hand, TCRBV21 was detected by A-PCR only, probably reflecting a poor TCRBV 21 primer amplification as observed in controls (Fig. $2 A$ ). In our conditions, the TCRBV-specific amplification is rather qualitative than quantitative. The most striking evidence for this aspect is 
A

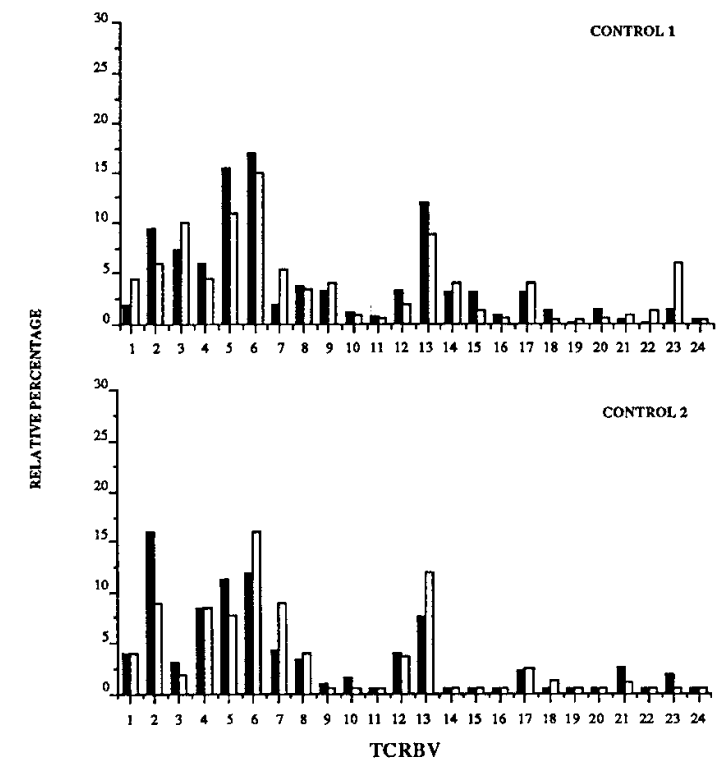

C

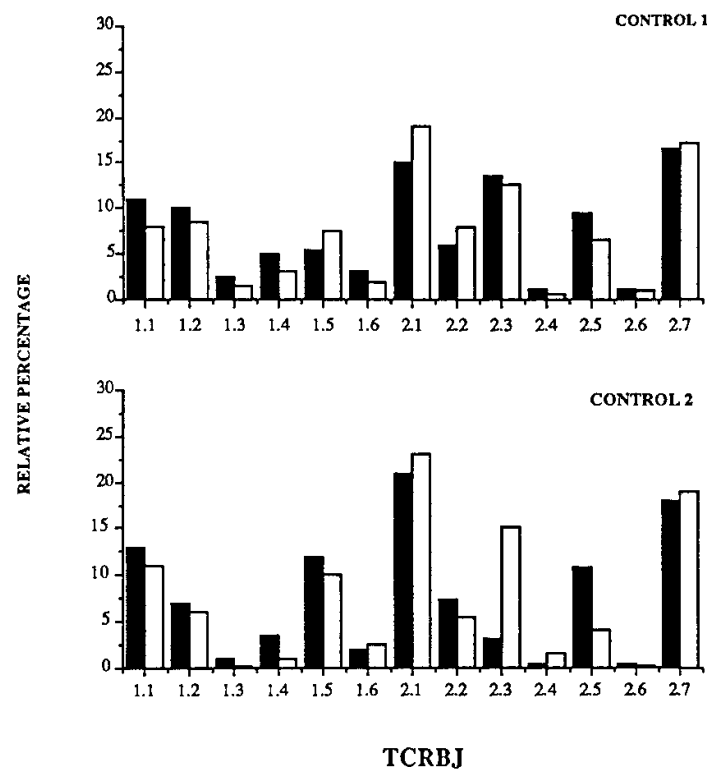

B
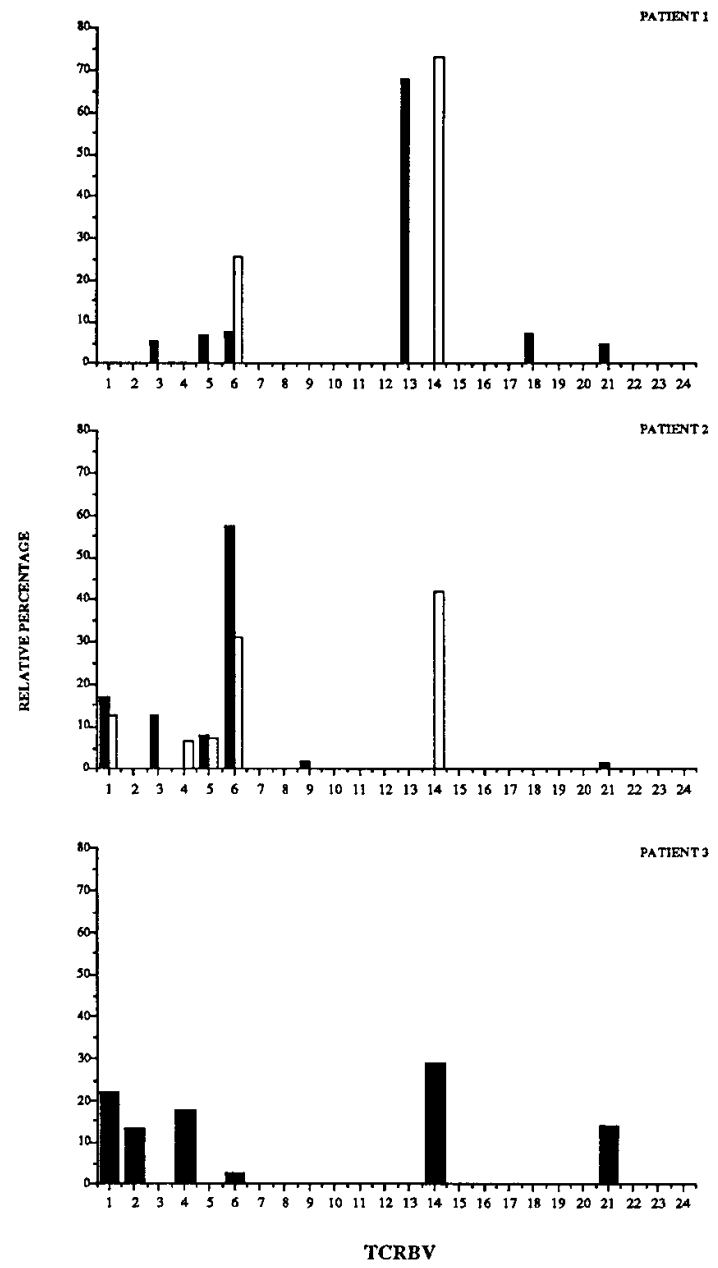

D
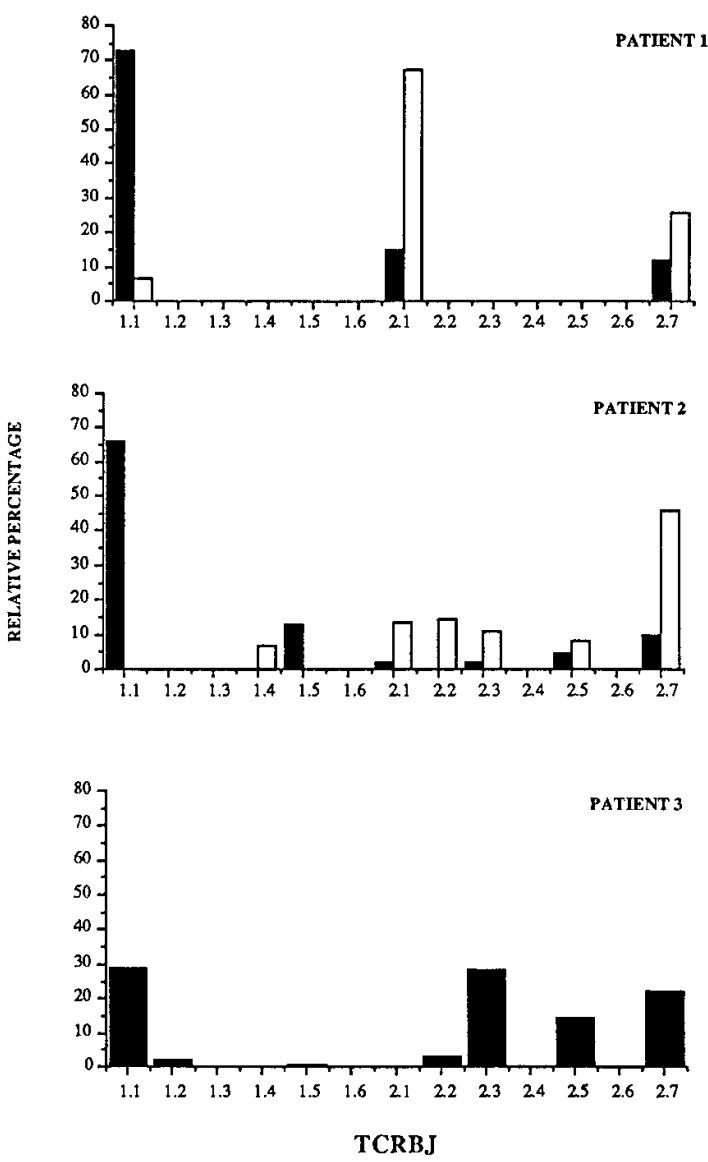
Patient 2

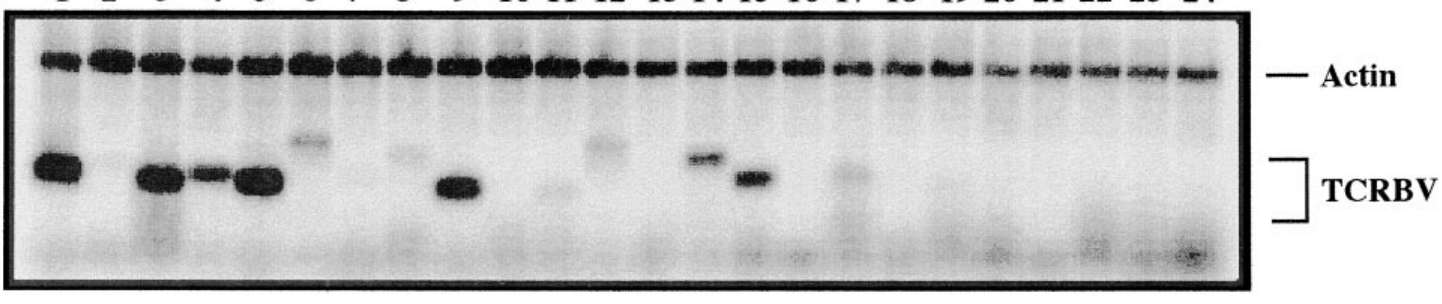

$\begin{array}{lllllllllllllllllllllllll}\text { TCRBV } & 1 & 2 & 3 & 4 & 5 & 6 & 7 & 8 & 9 & 10 & 11 & 12 & 13 & 14 & 15 & 16 & 17 & 18 & 19 & 20 & 21 & 22 & 23 & 24\end{array}$

Control

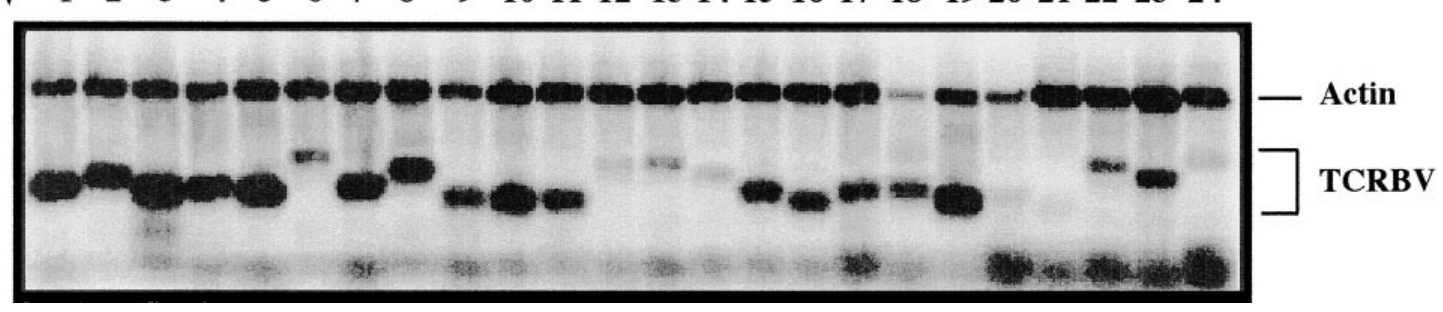

B

$\begin{array}{llllllllllllllllllllllllllllll}\text { TCRVA } & 1 & 2 & 3 & 4 & 5 & 6 & 7 & 8 & 9 & 10 & 11 & 12 & 13 & 14 & 15 & 16 & 17 & 18 & 19 & 20 & 21 & 22 & 23 & 24 & 25 & 26 & 27 & 28\end{array}$

Patient 2

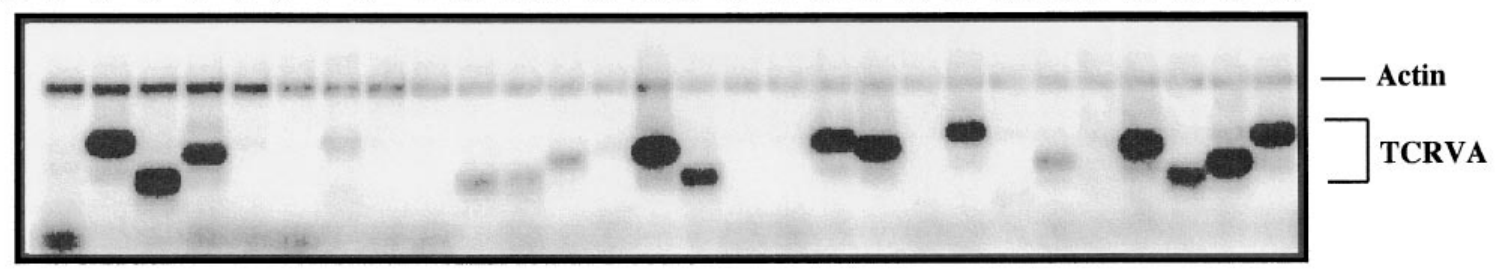

$\begin{array}{lllllllllllllllllllllllllllll}\text { TCRVA } & 1 & 2 & 3 & 4 & 5 & 6 & 7 & 8 & 9 & 10 & 11 & 12 & 13 & 14 & 15 & 16 & 17 & 18 & 19 & 20 & 21 & 22 & 23 & 24 & 25 & 26 & 27 & 28\end{array}$

Control

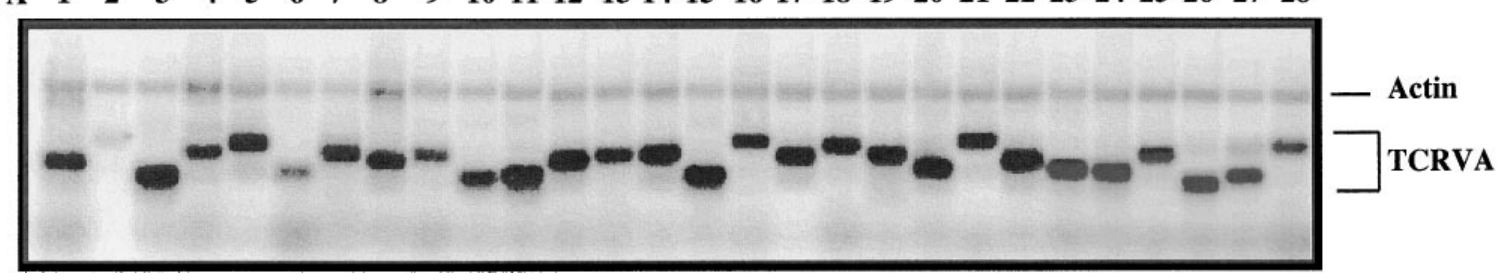

Figure 2. TCRBV $(A)$ and TCRAV $(B)$ amplifications detected by Southern blot analysis on PBMC from patient 2 (top) or control (bottom).

given by the TCRBV9 subfamily detection. This subfamily is detected below $10 \%$ using both A-PCR and immunofluorescence ( 5 and $7 \%$, respectively) as opposed to the major signal obtained using the TCRBV-specific amplification. Altogether these methods allowed us to detect 12 out of 24 TCRBV families in patient 2. Hence, nondetection reflects an absence of cells bearing the corresponding TCRBV family. As an example, TCRBV2 is consistently expressed in $\sim 10 \%$ of normal peripheral lymphocytes $(9,10,14,15)$, and this was confirmed in our controls. The absence of TCRBV2 ${ }^{+} \mathrm{T}$ cells in patient 2 was confirmed both by TCRBV2-specific PCR (Fig. 2) and by anti-TCRBV2-specific immunofluorescence (Table I).

HLA-DR staining of $\mathrm{CD}^{+}$cells indicated that $30-57 \%$ of patients' $T$ cells were activated, compared with only $5 \%$ of control T cells. Therefore, it was important to assess separately the TCRBV repertoire in these $\mathrm{HLA}_{-} \mathrm{DR}^{+}$and $\mathrm{HLA}-\mathrm{DR}^{-}$ subsets. Comparative analysis of six different TCRBV families (TCRBV1-6) used in sorted $\mathrm{CD}^{+}, \mathrm{CD}^{+} \mathrm{DR}^{+}$, and $\mathrm{CD} 4^{+} \mathrm{DR}^{-}$cells from patient 2 yielded no significant difference using A-PCR. Therefore, these activated HLA-DR ${ }^{+} \mathrm{T}$ cells did not seem to bias the overall TCRBV repertoire, despite their elevated number and potentially higher mRNA content (16).

The TCRBV repertoire in patient 2 was also determined by immunofluorescence analysis using a panel of 18 anti-TCRBV monoclonal antibodies. The results for most TCRBV families closely correlated with those obtained by the A-PCR-based method (Fig. $1 B$ and Table I). TCRBV12, which was not detected by A-PCR but represented only $3 \%$ of $\mathrm{CD}^{+} \mathrm{T}$ cells in the immunofluorescence study, was the only exception.

Then, it was of interest to assess the TCRAV repertoire. Since few anti-TCRAV antibodies are available and given the

Figure 1. Relative TCRBV $(A$ and $B)$ and TCRBJ $(C$ and $D)$ transcript levels in peripheral $\mathrm{CD} 4^{+}($black bars $)$and $\mathrm{CD} 8^{+}($white bars $)$T cells from $(A$ and $C)$ representative control and $(B$ and $D)$ three patients with Omenn's syndrome. 
Table I. Immunofluorescence Study of the TCRBV Repertoire in $\mathrm{CD}^{+}$and $\mathrm{CD}^{+} \mathrm{T}$ Cells from Patient 2

\begin{tabular}{lrrc}
\hline & \multicolumn{2}{c}{ Patient 2 } & Controls* \\
\cline { 2 - 3 } TCRBV & $\mathrm{CD}^{+}$ & $\mathrm{CD}^{+}$ & $\mathrm{CD}^{+}$ \\
\hline 2 & 0 & 0 & $7.5-10.9 \%$ \\
3 & 4 & 0 & $0-8 \%$ \\
5.1 & 0 & 0 & $4.2-7.2 \%$ \\
$5.2+5.3$ & 5 & 5 & $1-5 \%$ \\
5.3 & 0 & 0 & $1-5 \%$ \\
6.1 & 42 & 17 & $2.5-4.4 \%$ \\
6.7 & 0 & 0 & $1-5 \%$ \\
8 & 0 & 0 & $2.6-5.1 \%$ \\
9 & 7 & 0 & $1.6-3.2 \%$ \\
12 & 3 & 0 & $1.1-1.9 \%$ \\
13.1 & 0 & 0 & $1.8-3.3 \%$ \\
13.6 & 0 & 0 & $0.9-1.9 \%$ \\
14 & 5 & 47 & $2.2-5.6 \%$ \\
16 & 0 & 0 & $0.4-1.1 \%$ \\
17 & 0 & 0 & $3.3-7 \%$ \\
18 & 0 & 0 & $0.7-1.4 \%$ \\
20 & 0 & 0 & $0-2.4 \%$ \\
21 & 06 & 0 & $2.2-3.6 \%$ \\
Total & & & $34-82 \%$ \\
& 0 & & \\
\hline & 0 & 0 &
\end{tabular}

*According to the manufacturer.

fact that up to one-third of peripheral $\mathrm{T}$ cells can express two productive alpha chains (17), we could not use a quantitative approach. Therefore, we limited our study to a qualitative analysis of patient 2. Results of a typical experiment are depicted in Fig. 2 B. All TCRAV subfamilies tested can be amplified in controls, but only a restricted pattern of TCRAV was detected in patient 2. Comparing results obtained with the same approach showed that 17 out of 28 TCRAV subfamilies $(2-4,7,10-12,14,15,18,19,21,23,25-28)$ and 12 out of 24 TCRBV subfamilies $(1,3-6,8,9,11,12,14,15,17)$ were detected to different extents (as compared with controls). This is in keeping with $30 \%$ of $\mathrm{T}$ cells expressing two productive alpha chains.

To further characterize TCRB chain structure in Omenn's syndrome, the TCRBC libraries were screened with a panel of TCRBJ-specific probes. As expected from the results of previous studies $(11,14,18)$, all TCRBJ segments were expressed in $\mathrm{CD}^{+}$and $\mathrm{CD}^{+}{ }^{+} \mathrm{T}$ cells from controls, with most frequencies comprised between 1 and 10\% (range 0.5-20\%). Expression of TCRBJ2S1 and TCRBJ2S7 predominated (Fig. $1 C$ ). TCRBJ segment usage was drastically restricted and biased in $\mathrm{CD} 4^{+}$ and $\mathrm{CD}^{+} \mathrm{T}$ cells from patients 1 and 2 and in unsorted PBMC from patient 3 (Fig. 1 D). Superimposition of hybridization patterns obtained consecutively on the same TCRBV libraries with TCRBV- and TCRBJ-specific probes indicated that most of the TCRBV segments were preferentially associated with one TCRBJ segment. For example, the 171 TCRBV13 ${ }^{+}$clones in the $\mathrm{CD}^{+} \mathrm{T}$ cell library of patient 1 all hybridized with the TCRBJ1S1 probe, thus suggesting monoclonality within this TCRBV family. Other predominant, although not exclusive, associations were suggestive of oligoclonal TCRBV families, such as TCRBV14-TCRBJ2S7 (71/115 TCRBV14 ${ }^{+}$clones were $\mathrm{TCRBJ} 2 \mathrm{~S}^{+}$) in $\mathrm{CD} 8^{+} \mathrm{T}$ cells of patient 2 . Such a predominant TCRBV-TCRBJ association was never found in controls with the same screening approach.

Taken together, the pattern of the TCRBV and TCRBJ repertoire suggested a highly restricted diversity of the TCRB chain and, consequently, of the T cell population in Omenn's syndrome, and prompted us to examine the sequence of these TCRBC-positive clones in more detail.

Sequence analysis of TCRBVJ junctions in Omenn's syndrome. To confirm the oligoclonal nature of the T cell population in Omenn's syndrome, the nucleotide sequences of most $\mathrm{TCRBV}^{+}$clones were determined in the three patients (Table II). When redundant CDR3 structures were found, the $5^{\prime}$ ends of the corresponding clones (containing the $G$ tail and the cDNA start) were sequenced. Differences in $\mathrm{G}$ tail length or a different cDNA start site always confirmed that these clones arose from independent PCR products (data not shown). The control TCRBC libraries generated by A-PCR were also free of redundant clones, as reported previously (11). All the sequenced clones resulted from in-frame rearrangements, and were thus likely to correspond to productive TCRB transcripts. The structure of the junctions appeared to be normal, with $\mathrm{N}$ nucleotides between $\mathrm{V}$ and $\mathrm{D}$ or $\mathrm{D}$ and $\mathrm{J}$ regions in most cases.

The most striking finding concerned patient 3 , in whom sequence analysis demonstrated a single junctional sequence for each of the five TCRBV expressed in T cells. This argued that the $\mathrm{T}$ cell population in this patient consisted of only five different $\mathrm{T}$ cell clones. In the case of TCRBV1 and TCRBV14, monoclonality was further demonstrated with the CDR3-specific probes DIVB1 and DIVB14, which hybridized, respectively, 67 out of $67 \mathrm{TCRBV}^{+}$and 55 out of $55 \mathrm{TCRBV}^{+}$ clones (Table II). In patient 1 , the TCRBV13 family accounted for $68 \%$ of the $\mathrm{CD}^{+} \mathrm{T}$ cell population. Sequence analysis of 11 independent $\mathrm{TCRBV}^{+} 3^{+}$clones indicated a single VDJ structure. The monoclonality was again confirmed by hybridization with the DIVB13 CDR3-specific probe, which detected 160 out of $160 \mathrm{TCRBV}^{+} 3^{+}$clones. The same was true for TCRBV14, which accounted for as many as $75 \%$ of $\mathrm{CD}^{+} \mathrm{T}$ cells in the same patient. Sequence analysis of five independent clones identified only two different junctions, and the DIVB14a and DIVB14b probes specific for each CDR3 hybridized 160 out of 176 and 16 out of 176 TCRB14+ clones, respectively. This confirmed the absence of other junctional sequences in these clones. According to the other sequences (except for the TCRBV6 family in CD4 ${ }^{+} \mathrm{T}$ cells, which comprised two clones) the other five TCRBV families detected in patient 1 were most likely monoclonal (Table II). In patient 2, sequence analysis showed that each of the seven TCRBV families detected by hybridization reflected the presence of one (TCRBV3 and TCRBV9 in $\mathrm{CD}^{+}$and TCRBV1 in $\mathrm{CD}^{+}$), two (TCRBV1, TCRBV5, and TCRBV21 in $\mathrm{CD}^{+}$), or at most three (TCRBV6 in CD4 ${ }^{+}$and TCRBV6 and TCRBV14 in $\mathrm{CD}^{+}$) different clones (Table II). Comparisons of CDR3 sequences revealed three types of homologies. As a first type we found homologies between clones of the same patient. They used the same TCRBV segment and exhibited an identical CDR3 length. Those are represented by sequences 17 and 18 (TCRBV6S1; 12 amino acids) and sequences 20 and 21 (TCRBV21; 10 amino acids) in the $\mathrm{CD}^{+}$subpopulation of patient 2. A second group of homologies is made of sequences found in different patients and exhibiting the previous charac- 


\begin{tabular}{|c|c|c|c|c|c|c|c|}
\hline & & & CDR3 & & & & \\
\hline Patie & $\mathrm{D}^{+}$ & & & & & 1 & 2 \\
\hline Seq\# & TCRBV & & & & TCRBJ & & \\
\hline & & C A $\quad$ S & $\begin{array}{llllllllll}S & S & Q & G & Q & V & Y & E & Q & Y\end{array}$ & $\mathrm{~F}$ & & & \\
\hline 1 & $3 \mathrm{~S} 1$ & TGTGCCAGC & AGTTCCCAgggacaggTCTACGAGCAGTAC & TTC & $2 \mathrm{~S} 7$ & $4 / 4$ & \\
\hline & & $\begin{array}{lll}\mathrm{C} & \mathrm{A} & \mathrm{T}\end{array}$ & $\begin{array}{lllllllll}G & T & D & I & S & Y & E & Q & Y\end{array}$ & $\mathrm{~F}$ & & & \\
\hline 2 & $5 \mathrm{~S} 1$ & TGCGCCA CA & GGAACCgacaTCTCCTACGAGCAGTAC & $\mathrm{TTC}$ & $2 \mathrm{~S} 7$ & $5 / 5$ & \\
\hline & & C A S & $\begin{array}{llllllllll}S & \mathrm{~L} & \mathrm{~T} & \mathrm{R} & \mathrm{D} & \mathrm{G} & \mathrm{Y} & \mathrm{N} & \mathrm{E} & \mathrm{Q}\end{array}$ & $\mathrm{F}$ & & & \\
\hline 3 & $6 \mathrm{~S} 1$ & TGTGCCAGC & AGCTTAACgagggACGGTTACAATGAGCAG & TTC & $2 \mathrm{~S} 1$ & $2 / 6$ & \\
\hline & & C A S & $\begin{array}{llllllll}S & D & G & A & H & N & E & Q\end{array}$ & $\mathrm{~F}$ & & & \\
\hline 4 & $6 \mathrm{~S} 1$ & TGTGCCAGC & AGCGACggggcCCACAATGAGCAG & TTC & $2 \mathrm{~S} 1$ & $4 / 6$ & \\
\hline & & C A S & $\begin{array}{lllllll}\mathrm{S} & \mathrm{H} & \mathrm{P} & \mathrm{N} & \mathrm{T} & \mathrm{E} & \mathrm{A}\end{array}$ & $\mathrm{F}$ & & & \\
\hline 5 & 13 & TGTGCCAGC & AGCCACCCGAACACTGAAGCT & $\mathrm{TTT}$ & 1S1 & $11 / 11$ & $160 / 160$ \\
\hline & & C A S & $\begin{array}{llllllll}G & P & Y & Y & N & N & E & Q\end{array}$ & $\mathrm{~F}$ & & & \\
\hline 6 & $18 \mathrm{~S} 1$ & TGTGCCAGC & TCACCCACGTCTGgggggсCTTATTATAACAATGAGCAG & TTC & $2 \mathrm{~S} 1$ & $3 / 3$ & \\
\hline & & C A S & $\begin{array}{llllllll} & S & \text { L } & \text { G } & \text { G } & \text { A } & \text { E } & \text { A }\end{array}$ & $\mathrm{F}$ & & & \\
\hline 7 & $21 \mathrm{~S} 1$ & TGTGCCAGC & AGCTTAGggggcGCTGAAGCT & TTT & 1S1 & $3 / 3$ & \\
\hline Patier & $\mathrm{D}^{+}$ & & & & & 1 & 2 \\
\hline Seq\# & TCRBV & & & & TCRBJ & & \\
\hline 8 & & C A S & $\begin{array}{lllllll}S & L & S & Y & E & Q & Y\end{array}$ & $\mathrm{~F}$ & & & \\
\hline & $6 \mathrm{~S} 1$ & TGTGCCAGC & AGCTTGTCCTACGAGCAGTAC & TTC & $2 \mathrm{~S} 7$ & $5 / 5$ & \\
\hline & & C A S & $\begin{array}{lllllllll}R & L & L & P & L & N & T & E & A\end{array}$ & $\mathrm{~F}$ & & & \\
\hline 9 & $14 \mathrm{~S} 1$ & TGTGCCAGC & AGGTTACTGCCCCTGAACACTGAAGCT & TTT & 1S1 & $2 / 10$ & $16 / 176$ \\
\hline & & C A S & 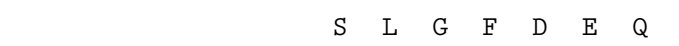 & $\mathrm{F}$ & & & \\
\hline 10 & $14 \mathrm{~S} 1$ & TGTGCCAGC & AGTTTggggTTCGATGAGCAG & TTC & $2 \mathrm{~S} 1$ & $8 / 10$ & $160 / 176$ \\
\hline Patie & $\mathrm{D} 4^{+}$ & & & & & 1 & \\
\hline Seq\# & TCRBV & & & & TCRBJ & & \\
\hline & & C A S & $\begin{array}{llllllllll}S & P & R & T & G & Q & W & P & Q & H\end{array}$ & $\mathrm{~F}$ & & & \\
\hline 11 & 1 & TGTGCCAGC & AGCCCGAggacaggCCAATGGCCCCAGCAT & $\mathrm{TTT}$ & 1S5 & $3 / 5$ & \\
\hline & & C A S & $\begin{array}{llllllll}\mathrm{S} & \mathrm{V} & \mathrm{E} & \mathrm{E} & \mathrm{T} & \mathrm{Q} & \mathrm{Y}\end{array}$ & $\mathrm{F}$ & & & \\
\hline 12 & 1 & TGTGCCAGC & AGCGtagAAGAGACCCAGTAC & TTC & $2 \mathrm{~S} 5$ & $2 / 5$ & \\
\hline & & C A S & $\begin{array}{lllllllll}S & L & L & G & G & A & K & A & F\end{array}$ & $\mathrm{~F}$ & & & \\
\hline 13 & 3 & TGTGCCAGC & AGCTTATTGgggggcGCGAAAGCTTTC & TTT & $1 \mathrm{~S} 1$ & $3 / 3$ & \\
\hline & & $\begin{array}{lll}C & A & Q\end{array}$ & $\begin{array}{lllllllllll}G & F & G & E & R & N & Q & P & Q & H\end{array}$ & $\mathrm{~F}$ & & & \\
\hline 14 & 5 & TGTGCC CAG & GGCTTCGgggagAGGAATCAGCCCCAGCAT & TTT & 1S5 & $2 / 4$ & \\
\hline & & $\begin{array}{lll}C & A & Q\end{array}$ & $\begin{array}{lllllll}G & L & S & Y & E & Q & Y\end{array}$ & $\mathrm{~F}$ & & & \\
\hline 15 & 5 & TGTGCC CAA & GGATTGTCCTACGAGCAGTAC & TTC & $2 \mathrm{~S} 7$ & $2 / 4$ & \\
\hline & & C A S & $\begin{array}{lllllll}S & T & S & Y & E & Q & Y\end{array}$ & $\mathrm{~F}$ & & & \\
\hline 16 & $6 \mathrm{~S} 6$ & TGTGCCAGC & AGCACCTCCTACGAGCAGTAC & TTC & $2 \mathrm{~S} 7$ & $4 / 4$ & \\
\hline & & C A S & $\begin{array}{llllllllllll}S & L & R & P & G & Q & G & N & T & E & A & F\end{array}$ & $\mathrm{~F}$ & & & \\
\hline 17 & $6 \mathrm{~S} 1$ & TGTGCCAGC & AGCTTAAGACCgggacagggGAACACTGAAGCTTTC & TTT & 1S1 & $5 / 8$ & \\
\hline & & C A S & $\begin{array}{llllllllllll}S & \mathrm{~L} & \mathrm{~V} & \mathrm{~L} & \mathrm{P} & \mathrm{V} & \mathrm{G} & \mathrm{R} & \mathrm{T} & \mathrm{E} & \mathrm{A} & \mathrm{F}\end{array}$ & $\mathrm{F}$ & & & \\
\hline 18 & $6 \mathrm{~S} 1$ & TGTGCCAGC & AGCTTAGTACTCCCAGTggggaggACTGAAGCTTTC & $\mathrm{TTT}$ & 1S1 & $3 / 8$ & \\
\hline & & C A S & $\begin{array}{lllllllll}S & Y & S & N & Q & P & Q & H\end{array}$ & $\mathrm{~F}$ & & & \\
\hline 19 & 9 & TGTGCCAGC & AGCTATAGCAATCAGCCCCAGCAT & $\mathrm{TTT}$ & 1S5 & $5 / 5$ & \\
\hline & & C A S & $\begin{array}{llllllllll}S & S & R & R & M & N & T & E & A & F\end{array}$ & $\mathrm{~F}$ & & & \\
\hline 20 & $21 \mathrm{~S} 1$ & TGTGCCAGC & AGCTCGCGAcggATGAACACTGAAGCTTTC & TTT & $1 \mathrm{~S} 1$ & $1 / 3$ & \\
\hline & & C A S & $\begin{array}{llllllllll}S & \mathrm{~L} & \mathrm{D} & \mathrm{L} & \mathrm{G} & \mathrm{T} & \mathrm{D} & \mathrm{T} & \mathrm{Q} & \mathrm{Y}\end{array}$ & $\mathrm{F}$ & & & \\
\hline 21 & $21 \mathrm{~S} 1$ & TGTGCCAGC & AGCTTAGATTTGGGCACAGATACGCAGTAT & TTT & $2 \mathrm{~S} 3$ & $2 / 3$ & \\
\hline
\end{tabular}

(Continued)

teristics (same TCRBV segment, identical CDR3 length). Two subgroups were found in clones using TCRBV14. Sequences $10\left(\mathrm{CD}^{+} \mathrm{T}\right.$ cells from patient 1$)$ and $27\left(\mathrm{CD}^{+} \mathrm{T}\right.$ cells from patient 2) with a CDR3 length of 7 amino acids, and sequences $9\left(\mathrm{CD}^{+} \mathrm{T}\right.$ cells from patient 1$), 28\left(\mathrm{CD}^{+} \mathrm{T}\right.$ cells from patient 2), and 32 (PBL from patient 3 ) with a CDR3 made of 9 amino acids. These two types of homologies could be representative of antigen-driven selections. A third type of CDR3 homology was observed for sequences $8,15,16$, and 26 (bottom of Table II). Although these clones belong to different subpopulations and expressed different TCRBV, they all used the TCRBJ2S7 segment and exhibited a 7-amino acid long CDR3. More strikingly, an hydroxylic residue (serine or threonine) was always found at position 3 in these CDR3s. Two additional sequences 
$\mathrm{CDR} 3$

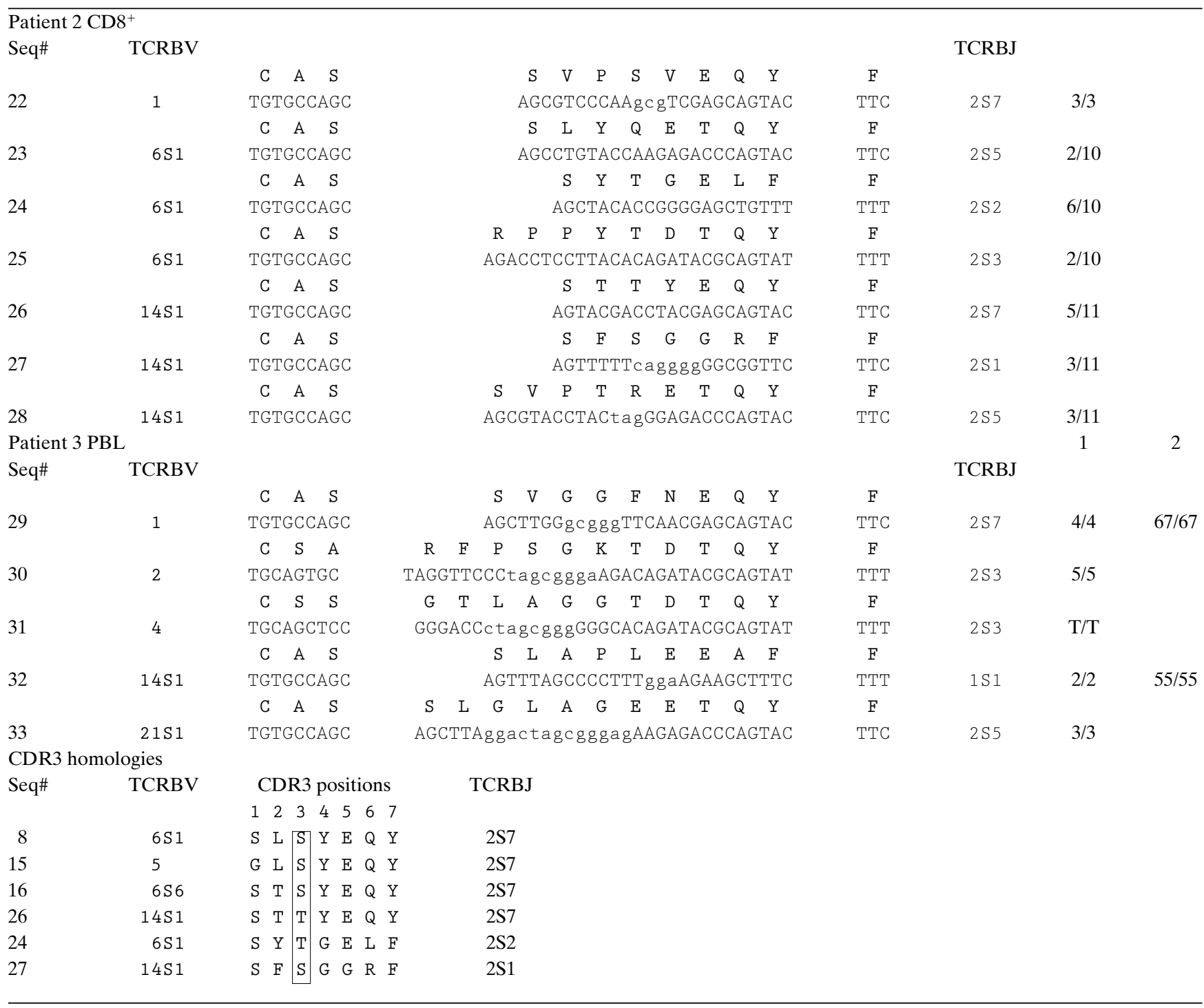

1, X/Y, X times found in Y sequences of a given TCRBV. 2, $\mathrm{x} / \mathrm{y}, \mathrm{x}$ times found in $\mathrm{y}$ TCRBV clones after hybridization with junction-specific primer.

(24 and 27) showed the same ( 7 amino acids and a serine or a threonine at position 3) although using another TCRBJ segment. These homologies between clones belonging either to the $\mathrm{CD} 4$ or the CD8 subpopulation would rather suggest a superantigen-driven selection or a nonconventional antigen stimulation. It was shown recently that Mycoplasma or Urtica doica superantigens could select the CDR3 and TCRBJ segment, respectively $(19,20)$.

$T C R B V$ repertoire of tissue-infiltrating lymphocytes. To determine whether the highly restricted number of $\mathrm{T}$ cell clones observed in peripheral blood of patients with Omenn's syndrome was representative of the whole $\mathrm{T}$ cell population, we performed an immunohistochemical study with 18 antiTCRBV mAbs on lymph node, spleen, skin, and intestine samples available from patient 2 (Table III). The results were compared with the peripheral blood lymphocyte TCRBV repertoire. Six different TCRBV families (TCRBV 3, 5.2, 6.1, 9, 12, and 14) were detected in tissue-infiltrating lymphocyte. Only a few cells were stained by the anti-TCRBV14 antibody, but the TCRBV14S1J1S1 amplification products using genomic DNA from spleen and skin (data not shown) indicated that TCRBV14 T cells were actually present in tissues. The other 12 anti-TCRBV mAbs which reproducibly stained positive controls did not reveal the presence of additional TCRBV families in tissue-infiltrating lymphocytes as compared with PBMC from this patient.

In the intestine, the $T$ cell infiltrate, mostly located in the lamina propria with a few scattered intraepithelial cells, was too sparse to allow comparison of TCRBV families. Histology of lymph nodes and spleen showed the atrophy of follicles. The $T$ cell infiltrate was dense in the skin, with a majority of dermal $\mathrm{T}$ cells but also a significant fraction of $\mathrm{T}$ cells in the epidermis 
Table III. Immunohistochemical Study of TCRBV Repertoire in Tissue-infiltrating Lymphocytes from Patient 2

\begin{tabular}{|c|c|c|c|c|}
\hline TCRBV & Lymph node & Spleen & $\begin{array}{c}\text { Skin } \\
\text { (dermis/epidermis) }\end{array}$ & $\begin{array}{c}\text { Intestine } \\
\text { (lamina propria) }\end{array}$ \\
\hline 2 & - & - & - & - \\
\hline 3 & + & + & $+/-$ & + \\
\hline 5.1 & - & - & - & - \\
\hline $5.2+5.3$ & + & + & $+/+$ & + \\
\hline 5.3 & - & - & - & - \\
\hline 6.1 & + & + & $+/+$ & + \\
\hline 6.7 & - & - & - & - \\
\hline 8 & - & - & - & - \\
\hline 9 & + & - & - & - \\
\hline 12 & + & + & $+/-$ & + \\
\hline 13.1 & - & - & - & - \\
\hline 13.6 & - & - & - & - \\
\hline 14 & + & + & + & + \\
\hline 16 & - & - & - & - \\
\hline 17 & - & - & - & - \\
\hline 18 & - & - & - & - \\
\hline 20 & - & - & - & - \\
\hline 21 & - & - & - & - \\
\hline
\end{tabular}

(Fig. $3 A$ ). Immunophenotyping showed that the dermal infiltrate comprised both $\mathrm{CD}^{+}$and $\mathrm{CD}^{+} \mathrm{T}$ cells, whereas epidermal $\mathrm{T}$ cells were almost exclusively $\mathrm{CD}^{+}$(not shown). TCRBV3, 5S2, 6S1, and 12 were detected in the dermal infiltrate (Fig. 3, $B-E$ ). Lack of TCRBV3 and TCRBV12 in epidermal $\mathrm{T}$ cells was coherent, as these TCRBV segments were expressed only by $\mathrm{CD} 4^{+} \mathrm{T}$ cells in peripheral blood (Table I). TCRBV5S2 and 6S1 were detected in the dermis and the epidermis (Fig. 3, $C$ and $D$ ). Rare TCRBV 14 cells were detected in the epidermis (not shown).

Counting of TCRBV-positive cells in the skin showed approximately the same number (10-20/HPF) of TCRBV3-, 5S2-, and 6S1-positive cells. TCRBV12 (5-10/HPF) and TCRBV14 (1-5/HPF) positive cells were less numerous. It was in contrast to peripheral blood where TCRBV6S1- and TCRBV14S1-positive cells were much more numerous than cells of any other TCRBV family. This could suggest either a preferential homing of TCRBV3- and TCRBV5S2-positive cells in the skin or a homing of TCRBV6S1 and TCRBV14S1 in other tissues.

\section{Discussion}

The T cell population is profoundly abnormal in Omenn's syndrome. Thymus is virtually devoid of T cells. Lymphoid organs are atrophic. Activated T cells are numerous in blood and infiltrate mostly the skin and intestine to a lesser extent (2). These $\mathrm{T}$ cells are poorly responsive to antigens and allogeneic cells in vitro (2-4) and exhibit an abnormally biased Th2 cytokine pattern $(4,5)$. Their CD4 or CD8 phenotype is heterogeneous and mostly unpredictable. Some patients exhibit either a hyper$\mathrm{CD}^{+}$(as patient 3 herein) or $\mathrm{CD}^{+}$(as patient 1 herein) lymphocytosis or, sometimes, present a main $\mathrm{CD} 4^{-} \mathrm{CD}^{-} \mathrm{T}$ cell population $(3,4)$.

Discrete rearrangement patterns detected by Southern blot analysis of T cell DNA from four patients suggested that the
TCRBV repertoire might be restricted in Omenn's syndrome (2). Given the limited sensitivity of this technique, together with the impossibility of ascribing TCRBV segments, we used an A-PCR-based amplification method to analyze the entire TCRBV repertoire and the molecular structure of the TCRB chain in three patients with Omenn's syndrome. Also, we had the opportunity to analyze qualitatively the TCRVA usage in one case. An immunofluorescence study was also performed in this case. The close correlation between the results obtained by A-PCR and FACS ${ }^{\circledR}$ analyses ruled out PCR-related artifacts.

The drastic restriction of TCRBV usage found in the three patients confirmed our previous findings (2). We analyzed the TCRBV repertoire of $\mathrm{CD}^{+}$and $\mathrm{CD}^{+} \mathrm{T}$ cells separately, in patients 1 and 2, and found that the two subsets were equally affected by this restriction. Therefore, any conclusion can be driven related to $\mathrm{CD} 4$ or $\mathrm{CD} 8$ status. The TCRBV repertoire of $\mathrm{HLA}_{-\mathrm{DR}}^{+}$and HLA-DR ${ }^{-} \mathrm{CD}^{+}{ }^{+} \mathrm{T}$ cells from patient 2 was similar, ruling out the possibility that activated cells biased the global repertoire because of their potentially higher mRNA content (16). These skewed profiles of TCRBV usage, together with the expression of common TCRBV families 6, 14, and 21 in the three patients, are reminiscent of superantigenmediated stimulation $(15,21)$. Interestingly an evaluation of TCRBV repertoire by RT-PCR in a child with Omenn's syndrome previously showed a dramatic expansion of TCRBV14 ${ }^{+}$ cells (4). However, lack of TCRAV and TCRBJ repertoire analysis and sequencing did not allow for the ascription of this TCRBV profile to a superantigen or an antigen-mediated stimulation. In the present study the comparable restriction in TCRBJ usage, and the small number of CDR3 sequences within each TCRBV family, pointed to expansion of a limited number of clones possibly stimulated by a few recurrent antigenic determinants, as the CDR3 junction is generally associated with antigen recognition (22-24). This was supported by the identical CDR3 length among clones from patient 2 (TCRBV21 and TCRBV6S1) and among clones found in the three patients (TCRBV14 with a CDR3 made of 9 amino acids). However, the most striking finding concerned the CDR3 homology observed within a group of six clones. Although different TCRBV segments are used in these clones, they share similarities in length and amino acid composition with a conserved hydroxylic residue at position 3 . Since these clones belonged to the CD4 or the CD8 subpopulation, this similarity could reflect an unusual mechanism of selection. Superantigens were shown, in some instances, to influence both the CDR3 structure (19) and the TCRBJ segment usage (20). Therefore, finding a conserved position within CDR3s using in most cases the same TCRBJ segments could reflect a superantigen selection. On the other hand it could also reflect an expansion of $\mathrm{T}$ cells in response to a nonconventional antigen and/or in the context of a defective negative selection. Finally, the finding of a restricted TCRAV repertoire in patient 2 is in keeping with a proliferation of few $\mathrm{T}$ cell clones. This scarcity of TCR diversity, despite large numbers of $\mathrm{T}$ cells, probably explains the defective in vitro $\mathrm{T}$ cell responses to conventional antigens in Omenn's syndrome (2).

The presence of abundant activated $\mathrm{T}$ cells in skin and gut in Omenn's syndrome suggests that these tissues may express target antigen(s). Therefore, it was of interest to determine the TCRBV repertoire of the infiltrating $\mathrm{T}$ cells. The TCRBV families detected in the tissues of patient 2 were also very re- 

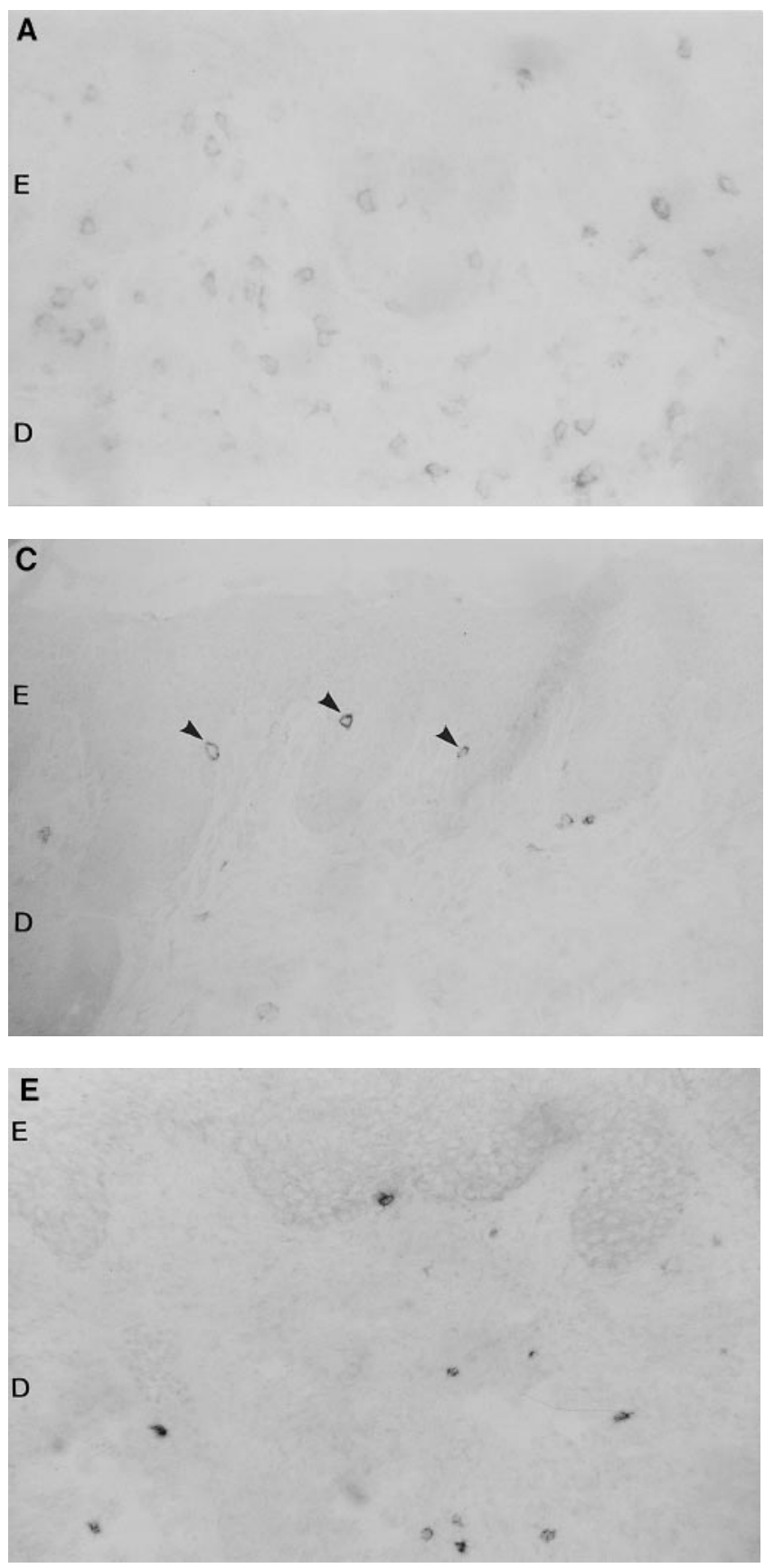

stricted and similar to those in this patient's peripheral blood. The overall $\mathrm{T}$ cell population consisted of no more than 11 different $\mathrm{CD}^{+}$and 7 different $\mathrm{CD}^{+}$clones in this particular patient. The relative overexpression of TCRBV3 and TCRBV5.2 in skin relative to peripheral blood indicates that accumulation of these TCRBV specificities may not simply result from nonspecific influx of circulating $\mathrm{T}$ cells but rather reflect antigendriven homing. Moreover, the selective location of different TCRBV clones in the dermis or the epidermis is also in accordance with a nonrandom tissue migration of these cells. Selective expansion of T cells in target organs has been observed in various autoimmune diseases (25-27). Part of the TCRBV profile in Omenn's syndrome might thus be attributed to an autoimmune reaction towards undetermined antigen(s). How-
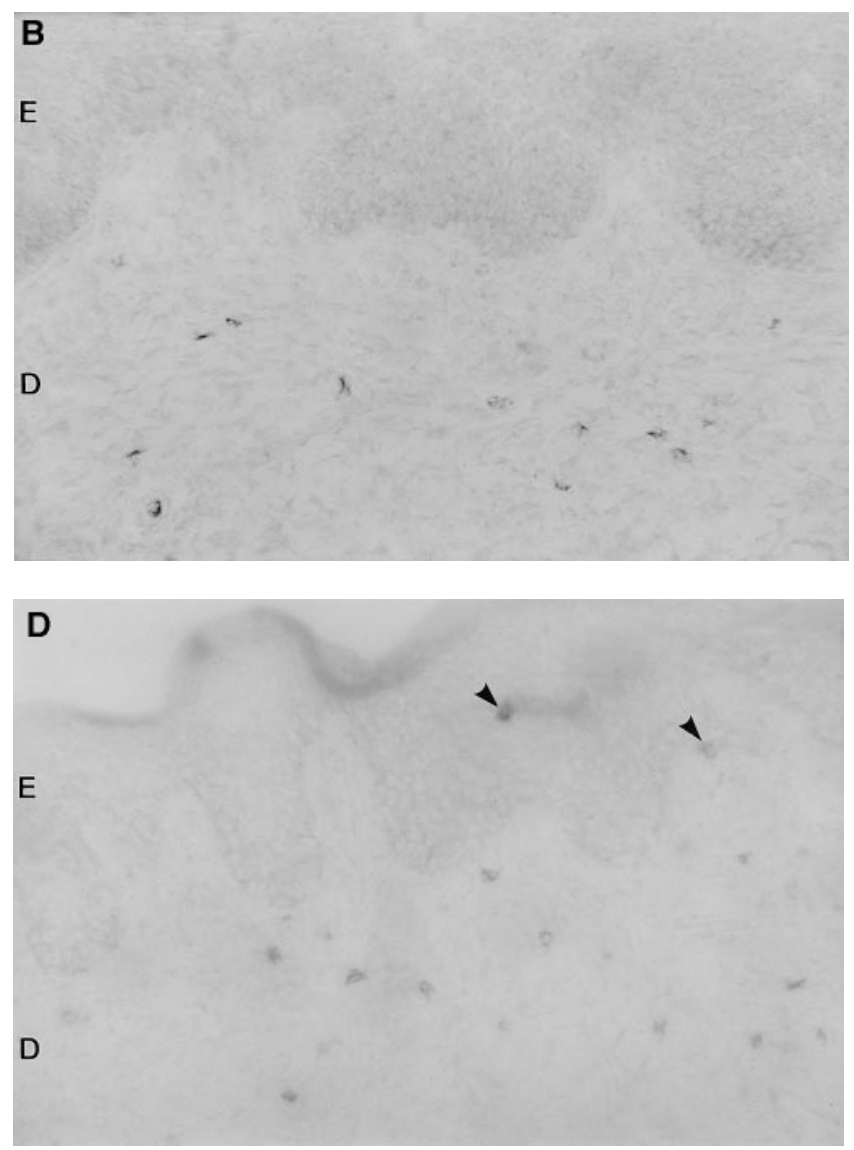

Figure 3. Immunohistochemical staining of a skin biopsy from patient 2 with $(A)$ anti-TCR $\alpha \beta,(B)$ anti-TCRBV3, $(C)$ anti-TCRBV5.2, $(D)$ anti-TCRBV6.1, and $(E)$ anti-TCRBV12. Note the presence of intraepidermal TCRBV5.2 and 6.1 cells (arrowheads).

ever, this would not explain the absence of an otherwise normal and diverse $\mathrm{T}$ cell population as seen in autoimmune diseases $(28,29)$ and after superantigen stimulation (15). A more likely explanation is that these clones arise in the context of a major defect in $\mathrm{T}$ cell development as in SCID condition. Omenn's syndrome would then represent either a "mild" form or a partial reversion of such SCID conditions. Omenn's syndrome may thus correspond to the phenotype induced by an incomplete blockade of $\mathrm{T}$ cell differentiation, followed by the expansion of a small number of autoreactive $\mathrm{T}$ cell clones that are poorly responsive in vitro. Additionally the stochastic coreceptor phenotype observed in patients suggest a $\mathrm{T}$ cell development in absence of either central or negative selection. Obtention of cellular clones from patients will certainly be 
helpful to get insights into functions of these peculiar lymphocyte populations.

\section{Acknowledgments}

We thank Dr. M. Bonneville for helpful discussion and advice. We are grateful to N. de Saint Sauveur for technical assistance.

This work was supported by institutional funding from INSERM and grants from Association de la recherche sur le cancer.

\section{References}

1. Omenn, G.S. 1965. Familial reticuloendotheliosis with eosinophilia. $N$. Engl. J. Med. 273:427-432.

2. De Saint Basile, G., F. Le Deist, J.P. De Villartay, N. Cerf-Bensussan, O. Journet, N. Brousse, C. Griscelli, and A. Fischer. 1991. Restricted heterogeneity of T lymphocytes in combined immunodeficiency with hypereosinophilia (Omenn's syndrome). J. Clin. Invest. 87:1352-1359.

3. Wirt, D.P., E.G. Brooks, S. Vaidya, G. Klimpel, T.A. Waldmann, and R. Goldbum. 1989. Novel T-lymphocyte population in combined immunodeficiency with features of graft versus host disease. N. Engl. J. Med. 321:370-374.

4. Melamed, I., A. Cohen, and C.M. Roifman. 1994. Expansion of $\mathrm{CD}^{+}{ }^{+} \mathrm{CD} 4^{-} \mathrm{CD} 8^{-} \mathrm{T}$ cell population expressing high levels of IL-5 in Omenn's syndrome. Clin. Exp. Immunol. 95:14-21.

5. Schandene, L., A. Ferster, F. Mascart-Lemone, A. Crusiaux, C. Gerard, A. Marchant, M. Lybin, T. Velu, E. Sariban, and M. Goldman. 1993. T helper 2-like cells and therapeutic effects of interferon gamma in combined immunodeficiency with hypereosinophilia (Omenn's syndrome). Eur. J. Immunol. 23: 56-60.

6. Le Deist, F., A. Fischer, A. Durandy, F. Arnaud-Battandier, C. Nezelof, M. Hamet, Y. De Prost, and C. Griscelli. 1985. Deficit immunitaire mixte et grave avec hypereosinophilie. Arch. Fr. Pediatr. 42:11-16.

7. Cavazzana-calvo, M., F. Le Deist, G. De Saint Basile, D. Papadopoulo, J De Villartay, and A. Fischer. 1993. Increased radiosensitivity of granulocyte macrophage colony-forming units and skin fibroblasts in human autosomal recessive severe combined immunodeficiency. J. Clin. Invest. 91:1214-1218.

8. Chomczynski, P., and N. Sacchi. 1987. Single-step method of RNA isolation by acid guanidium thiocyanate-phenol-chloroform extraction. Anal. Biochem. 162:156-159.

9. Rieux-Laucat, F., F. Le Deist, F. Selz, A. Fischer, and J.-P. de Villartay. 1993. Normal T cell receptor V $\beta$ usage in a primary immunodeficiency associated with HLA class II deficiency. Eur. J. Immunol. 23:928-934.

10. Bahadoran, P., F. Rieux-Laucat, F. Le Deist, S. Blanche, A. Fischer, and J. De Villartay. 1993. Lack of selective V $\beta$ deletion in peripheral CD4+ T cells of human immunodeficiency virus-infected infants. Eur. J. Immunol. 23:20412044.

11. Di Santo, J.P., F. Rieux-Laucat, A. Dautry-Varsat, A. Fischer, and G. De Saint Basile. 1994. Reduced expression of the human IL2R gamma chain results in an immunodeficiency with incomplete T-cell differentiation. Proc. Natl. Acad. Sci. USA. 91:9466-9470.

12. Genevée, C., A. Diu, J. Nierat, A. Caignard, P.Y. Dietrich, L. Ferradini, S. Roman-Roman, F. Triebel, and T. Hercend. 1992. An experimentally validated panel of subfamily-specific oligonucleotide primers (Va1-29/Vb1-24) for the study of human $\mathrm{T}$-cell receptor $\mathrm{V}$ gene segment usage by polymerase chain reaction. Eur. J. Immunol. 22:1261-1269.

13. Moss, P.A.H., and J.I. Bell. 1995. Sequence analysis of the human $\alpha \beta$ T-cell receptor CDR3 region. Immunogenetics. 42:10-18.

14. Rosenberg, W.M.C., P.A.H. Moss, and J.I. Bell. 1992. Variation in human $\mathrm{T}$ cell receptor $\mathrm{V} \beta$ and $\mathrm{J} \beta$ repertoire: analysis using anchor polymerase chain reaction. Eur. J. Immunol. 22:541-549.

15. Choi, Y., J.A. Lafferty, J.R. Clements, J.K. Todd, W.E. Gelfand, J.W. Kappler, P. Marrack, and B.L. Kotzin. 1990. Selective expansion of T cells expressing V $\beta 2$ in toxic shock syndrome. J. Exp. Med. 172:981-984.

16. Paillard, F., G. Sterkers, and C. Vaquero. 1990. Transcriptional and post-transcriptional regulation of TcR, CD4 and CD8 gene expression during activation of normal human T lymphocytes. EMBO (Eur. Mol. Biol. Organ.) J. 9:1867.

17. Padovan, E., G. Casorati, P. Dellabona, S. Meyer, M. Brockhaus, and A Lanzavecchia. 1993. Expression of two T cell receptor $\alpha$ chains: dual receptor T cells. Science. 262:422-424.

18. Grunewald, J., M. Jeddi-Tehrani, E. Pisa, C.H. Janson, R. Andersson, and $\mathrm{H}$. Wigzell. 1992. Analysis of $\mathrm{J} \beta$ gene segment usage by CD4+ and CD8+ human peripheral blood T lymphocytes. Int. Immunol. 4:643-650.

19. Hodtsev, A.S., Y. Choi, E. Spanopoulou, and D.N. Posnett. 1998. Mycoplasma superantigen is a CDR3-dependent ligand for the $\mathrm{T}$ cell antigen receptor. J. Exp. Med. 187:319-327.

20. Musette, P., A. Galelli, P. Truffa-Bachi, W. Peumans, P. Kourilsky, and G. Gachelin. 1996. The J $\beta$ segment of the T cell receptor contributes to the V $\beta$ specific $\mathrm{T}$ cell expansion caused by staphylococcal enterotoxin B and Urtica dioica superantigens. Eur. J. Immunol. 26:618-622.

21. Choi, Y., B. Kotzin, L. Herron, J. Callahan, P. Marrack, and J. Kappler 1989. Interaction of Staphylococcus aureus toxin "superantigens" with human T cells. Proc. Natl. Acad. Sci. USA. 86:8941-8945.

22. Chotia, C., D.R. Boswell, and A.M. Lesk. 1988. The outline structure of the T-cell alpha beta receptor. EMBO (Eur. Mol. Biol. Organ.) J. 7:3745-3755.

23. Engel, I., and S.M. Hedrick. 1988. Site-directed mutations in the VDJ junctional region of a $\mathrm{T}$ cell receptor beta chain cause changes in antigenic peptide recognition. Cell. 54:473-484.

24. Garcia, K.C., M. Degano, R.L. Stanfield, A. Brunmark, M.R. Jackson, P.A. Peterson, L. Teyton, and I.A. Wilson. 1996. An alphabeta T cell receptor structure at 2.5 A and its orientation in the TCR-MHC complex. Science. 274: 209-219.

25. Mantegazza, R., F. Andreeta, P. Bernasconi, F. Baggi, J.R. Oksenberg, O. Simoncini, M. Mora, F. Cornelio, and L. Steinman. 1993. Analysis of T cell receptor repertoire of muscle-infiltrating lymphocytes in polymyositis. J. Clin. Invest. 91:2880-2886.

26. Williams, W.V., Q. Fang, D. Demarco, J. Von Feldt, R.B. Zurier, and D.B. Weiner. 1992. Restricted heterogeneity of $\mathrm{T}$ cell receptor transcripts in rheumatoid arthritis synovium. J. Clin. Invest. 90:326-333.

27. Davies, T.F., A. Martin, E.S. Concepcion, P. Graves, L. Cohen, and A. Ben-Nun. 1991. Evidence for limited variability of antigen receptors on intrathyroidal T cells in autoimmune thyroid disease. N. Engl. J. Med. 1991:238-245.

28. Abe, J., B.L. Kotzin, K. Jujo, M.E. Melish, M.P. Glode, T. Kohsaka, and D.Y.M. Leung. 1992. Selective expansion of T-cells expressing T-cell receptor variable region V 32 and V $\beta 8$ in Kawasaki disease. Proc. Natl. Acad. Sci. USA. 89:4066-4070.

29. Abe, J., B.L. Kotzin, C.E. Meissner, M.E. Melish, M. Takahashi, D. Fulton, F. Romagne, B. Malissen, and D.Y.M. Leung. 1993. Characterization of T-cell repertoire changes in acute Kawasaki disease. J. Exp. Med. 177:791-796. 